NBER WORKING PAPER SERIES

AGGREGATE SPENDING AND THE TERMS OF TRADE: IS

THERE A LAURSEN-METZLER EFFECT?

Maurice Obstfeld

Working Paper No. 686

\author{
NATIONAL BUREAU OF ECONOMIC RESEARCH \\ 1050 Massachusetts Avenue \\ Cambridge MA 02138 \\ June 1981
}

I have had the benefit of very helpful conversations with Ralph Braid, Guillermo Calvo, Slobodan Djajic, Ronald Findlay, Paolo Kind, and Robert Mundell. Valuable suggestions were made by participants in a seminar at Harvard University. The research reported here was partially supported by a grant from the National Science Foundation. The research reported here is part of the NBER's research program in International Studies. Any opinions expressed are those of the author and not those of the National Bureau of Economic Research. 


\section{Aggregate Spending and the Terms of Trade: Is There a \\ Laursen-Metzler Effect?}

\section{Abstract}

This paper investigates the spending and current-account effects of permanent terms-of-trade shifts in a model where households maximize utility over an infinite planning period. In the framework we adopt, an economy specialized in production must experience a fall in aggregate spending and a current surplus when the terms of trade permanently deteriorate. The morel thus provides a sounter-eyample to the argument of Laursen and Setzler (1950) and Harberger (1950) that a permanent worsening in the terms of trade must produce a current-account deficit.

Maurice Obstfeld Department of Economics Columbia University New York, New York 10027 (212) $280-4190$ 


\section{Introduction}

In their classic 1950 analysis of the international transmission of business cycles under flexible exchange rates, ${ }^{1}$ Svend Laursen and Lloyd A. Metzler hypothesized a relationship between aggregate spending and the terms of trade that has come to occupy an important place in open-economy macroeconomics. This Laursen-Metzler effect was central to the early post-war writing on the theory of devaluation--notably that of Harberger [1950] and Alexander [1952]--and has, more recently, emerged in discussion of the external adjustment problem accompanying s.ifts in the ronati-re price of minufactured and primairy commodities. ${ }^{2}$ It predicts that an adverse movement in the terms of trade between domestic and foreign gooas will cause a rise in the home-goods value of expenditure, and, under conditions of complete specialization in production, a current-account deficit.

Laursen and Metzler based their hypothesis largely on statistical evidence that seemed to confirm Keynes' "fundamental psychological law" positing a stable relationship between current real income and consumption. ${ }^{3}$ According to this law, individuals adjust only gradually to a decline in real income, reducing saving as well as spending in an attempt to smooth their consumption stream. While recognizing that "a wide variety of different relations is consistent with rational behavior on the part of producers and consumers," Laursen and Metzler nonetheless adopted the Keynesian assumption, arguing that a deterioration of the terms of trade, which lowers real income, must lower saving as well. This paper takes as its starting point the proposition that the question raised by Laursen and Metzler can be answered only in a context of explicit, intertemporal utility maximization. To this end, we 
describe an economy in which households consume a non-produced exportable good and an imported foreign good, face given terms of trade, and maximize an integral of discounted instantaneous utilities over an infinite horizon by optimally allocating income each moment between current consumption and the accumulation of real claims on foreigners. The results of a permanent, unanticipated terms-of-trade change in this setting throw doubt on the general validity of the Laursen-Metzler relationship, for a worsening of the terms of trade between exports and imports is found to occasion a surplus, and not a deficit, in the current account. This implies that when net claims on future units of the foreign good are zero, so that the Laursen-Metzler assumption of complete specialization is valid, aggregate spending measured in units of the domestic good must fall.

The analysis pursued here is based on some special assumptions, due to Uzawa [1968], on the determination of agents' subjective rate of time preference; and its applicability is narrowed further by the exclusion of all but a single asset. Different assumptions about the structure of preferences and the range of assets may yield different results, and so, the outcome described here should be viewed only as an example of how the Laursen-Metzler effect may be reversed. 4 Nonetheless, the economic principle underlying this example is worth emphasizing, as it extends beyond the present context to any discussion of the relation among aggregate spending, income, and wealth. An unanticipated change in real income conveys new information about future consumption possibilities, and thus calls for a complete revision of the previous lifetime expenditure plan. The new plan may well entail a sharp change in current consumption, in contrast to the gradual adjustment implied by the 
Keynesian "psychological law." Barring further surprises, the path of future consumption will be smooth. But the arrival of new information renders all previous consumption levels irrelevant, if, as is assumed here, these have no influence on the household's welfare over the remainder of its lifetime. The paper is organized as follows. Section I describes the lifetime maximization problem of the typical household in a world of two consumption goods and perfect capital mobility, and derives necessary conditions for an optimal plan. Sèction II proves that there is a unique convergent path satisfying these necessary conditions, and that this path is optimal in the class of feasible paths. Section IrI uses this fact to determine the economy's resEonse to a permanent worsening in the terms of urade between inporis anc exports. Section IV extends the model to the case in which the home country faces an imperfect capital market, showing that the previous results are essentially unchanged. Finally, section $V$ presents some concluding remarks. 


\section{The Model}

The economy consists of identical households, each maximizing its utility over an infinite lifetime. Instantaneous utility is derived from consumption of two goods, one of which must be imported from abroad and one of which is available at home in fixed supply. Households may save by foregoing consumption and accumulating instead an internationally traded bond, assumed, without loss of generality, to be indexed to the foreign good.5. The economy is small, in the sense that it can influence neither the terms of trade between home and foreign goods nor the world rate of interest. Finally, it is assumed that these prices are expected to remain fixed forever. Pny price changes take households by surprise. 6 The representative household's instantaneous utility is a function

$$
U_{t}=U\left(c_{t}^{f}, c_{t}^{h}\right)
$$

of its consumption of foreign and home goods. U is taken to be positive, strictly increasing in both its arguments, strictly concave, and twice continuously differentiable. To avoid non-interior solutions to the household's lifetime consumption problem, we postulate that

$$
\lim _{c_{t}^{f} \rightarrow 0} U_{C_{t}^{f}}=\lim _{C_{t}^{h \rightarrow 0}} U_{C_{t}^{h}}=\infty
$$

The household's. objective is to maximize the discounted sum of future instantaneous utilities

(2) $\int_{0}^{\infty} U_{t} e^{-\Delta t} d t$, 
where

$$
\Delta_{t}=\int_{0}^{t} \delta_{s} d s
$$

and $\delta_{S}$ is the instantaneous subjective discount rate at time $s$. Like Uzawa [1968], we suppose $\delta_{s}$ to be a function

$$
\hat{o}_{S}=\delta\left(U_{S}\right)
$$

of utility at time $s$, where $\delta(\cdot)$ is positive and has the properties

(3) $\delta^{\prime}(U), \delta(U)-U \delta^{\prime}(U), \delta^{\prime \prime}(U)>0$.

While the conditions (3) are not the only ones consistent with the assumption of endogenous time preference, they turn out to be quite convenient in the present context. The reasons for imposing them will become clear during the course of our analysis. ${ }^{7}$ At each instant, the representative family is bound by a flow constraint linking any divergence between its income and its expenditure to its accumulation of claims on future units of the foreign good. Letting $b_{t}$ denote bond holdings at time $t, p$ the price of foreign goods in terms of domestic goods, $y$ the family's (fixed) endowment of the home good, and $r$ the international rate of interest, we may write this constraint as

(4) $\quad \dot{b}_{t}=y / p-c_{t}^{f}-c_{t}^{h} / p+r b_{t}$. 
The condition implies that for the economy as a whole, the capitalaccount deficit must equal the excess of income over expenditure.

The household is also bound by a second, less obvious, constraint on its program of saving and spending. The discounted sum of lifetime expenditure (measured in domestic goods, say) must be no greater than the capitalized value of lifetime income plus initial bond holdings,

$$
y / r+p b_{0} \geq \int_{0}^{\infty} e^{-r t}\left[p c_{t}^{f}+c_{t}^{h}\right] d t .
$$

The importance of this constraint can best be appreciated by contrasting the present infinite-horizon planning problem with a finite-horizon problem whose planning period ends at time $T$. In the latter setting, the family's budget constraint clearly implies that $b_{T}$ is nonnegative, for any lifetime borrowing must be repaid before death. But an infinitelylived family facing a perfect capital market may borrow and consume arbitrarily large amounts while always meeting its interest payments. Unless a condition such as (5) is imposed, its lifetime utility will be unbounded: no optimal program will exist.

To rule out this "paradox of borrowing" we shall impose the feasibility constraint that at each moment, the family's capitalized future income must exceed its indebtedness,

(6) $y / x+p b_{t} \geq 0$.

This restriction eliminates the option of running up an infinitely large debt. As we shall see in the next section, (6) is sufficient to ensure 
the existence of an optimal path satisfying (5). 8

The household's problem is to choose paths for $c^{f}, c^{h}$, and b that

(7) $\operatorname{maximize} \int_{0}^{\infty} U\left(c_{t}^{f}, c_{t}^{h}\right) e^{-\Delta_{t}} d t$

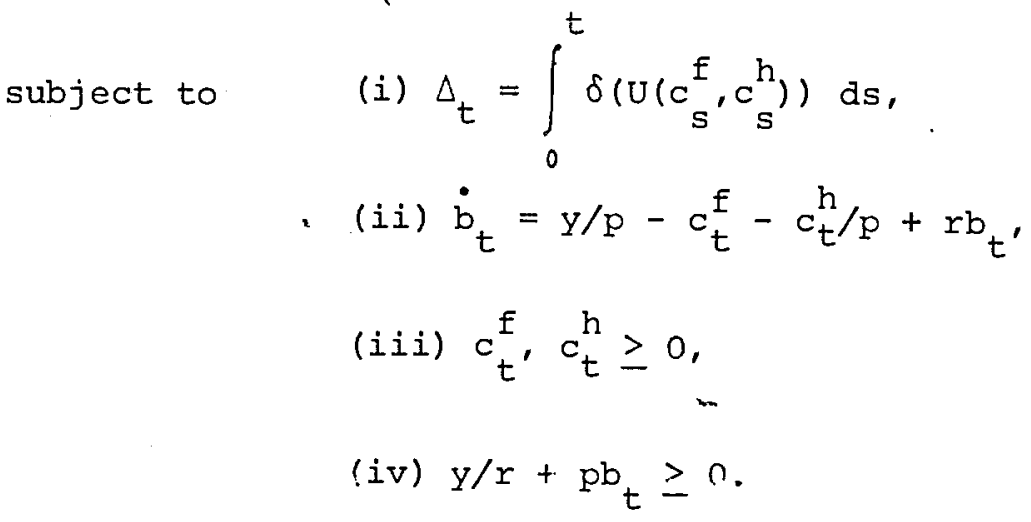

The number of households is for convenience taken to be 1 , so that the consumption and saving paths chosen by the representative household may be identified with those of the economy as a whole.

A few simplifications will facilitate solution of this maximization problem. In order to maximize lifetime welfare, the household must at each moment maximize its instantaneous utility, given relative prices and its chosen level of expenditure on consumption goods in general. Our first simplification is to replace the utility function in (2) with the indirect utility function

$$
V(p, z) \equiv \max \left\{U\left(c^{f}, c^{h}\right) \mid p c^{f}+c^{h}=z\right\}
$$

This device both reduces the dimensionality of our problem and allows us to focus on the variable of primary interest, expenditure in terms 
of the domestic good, $z$.

A second simplification is achieved by noting that assumption (1) implies constraints (iii) and (iv) can never be binding along an optimal trajectory, and may thus be ignored in deriving necessary conditions for optimality. In particular, spending on both goods must be zero whenever constraint (iv) binds, for at such a point, current income just suffices to meet interest payments on previous borrowing. A final simplification is obtained by changing variables in (7) from to $\Delta$, using the fact that

$$
d \Delta=\delta(V(p, z)) d t
$$

This reduces the family's problem to finding paths for $b$ and $z$ that

(8) $\operatorname{maximize} \int_{0}^{\infty} \frac{v(p, z)}{\delta(V(p, z))} e^{-\Delta} d \Delta$

subject to $\quad \frac{d b}{d \Delta}=\frac{(y-z) / p+r b}{\delta(V(p, z))}$.

Necessary conditions for a solution to (8) are readily derived using the Maximum Principle, provided that the problem's maximand is concave. That $\mathrm{V}(\mathrm{p}, \mathrm{z})$ is concave in $\mathrm{z}$ under our assumptions (so that $\left.v_{z z}<0\right)$ is demonstrated in the appendix. This fact, together with the restrictions (2) on the time preference function $\delta(\cdot)$, is sufficient to imply that 


$$
\frac{d^{2}}{d z^{2}}\left[\frac{V(p, z)}{\delta(V(p, z))}\right]=\frac{\left(\delta-V \delta^{\prime}\right)\left(\delta V_{z z}-2 \delta^{\prime}\left(V_{z}\right)^{2}\right)-V \delta^{\prime \prime} \delta\left(V_{z}\right)^{2}}{\delta^{3}}
$$

is negative.

To apply the Maximum Principle, we introduce the costate variable $\lambda$, which may be interpreted as the imputed value or shadow price of saving. 9 An optimal plan must at each moment equate the marginal utility of spending to the imputed value of an additional unit of saving, and must thus maximize the Hamiltonian

$$
H(b, z, \lambda)=\frac{V(p, z)+\lambda[(y-z) / p+r b]}{\delta(V(p, z))} .
$$

The chosen expenditure path therefore has the property that

$$
\partial \mathrm{H} / \partial \mathrm{z}=0
$$

at all $\Delta$, that is, that

(10) $\lambda=p v_{z}\left(1-V\left(\delta^{\prime} / \delta\right)\right) /\left(1+V_{z}\left(\delta^{\prime} / \delta\right)[y-z+r p b]\right)$.

In addition, the costate variable evolves according to the law of motion

$$
\frac{d\left(e^{-\Delta} \lambda\right)}{d \Delta}=-\frac{\partial\left(e^{-\Delta_{\mathrm{Fi}}}\right)}{\partial \mathrm{b}},
$$

or, reversing our initial change of variables, 
(11) $\dot{\lambda}_{t}=\lambda_{t}\left(\delta\left(v\left(p, z_{t}\right)\right)-r\right)$.

This condition states that the marginal rate of time preference must at each instant equal the rate of return on bonds plus "capital gains" $\dot{\lambda} / \lambda$. Differential equation (11), together with the flow constraint

$$
\dot{b}_{t}=\left(y-z_{t}\right) / p+r b_{t^{\prime}}
$$

must be satisfied by any optimal path.

$$
\text { While conditions (10), (11), - and (12) are necessarily satisfied by }
$$
an optimal program, they are not in themselves sufficient to guarantee optimality. The stock of bonds inherited from the past is predetermined at time $t=0$, and this fact provides one initial condition for the system. But an initial value of $\lambda$ is also required, and unless this shadow price is chosen correctly, a path that at each instant equates the marginal utility of consumption to the imputed value of saving will be suboptimal. Again, the problem is due to our assumption that the planning unit has an infinite life. If this life instead ended at time $T$, the terminal condition $b_{T}=0$ would enable us to solve backward for $\lambda_{0}$. But in the present context, no such restriction is available; and this difficulty calls into question the existence as well as the uniqueness of an optimal plan.

It is natural to focus our attention on the unique stationary state $(\bar{b}, \bar{z})$ of the economy, defined by the conditions

$$
\dot{\lambda}=\lambda(\delta(v(p, \bar{z})-r)=0,
$$


ensuring that the marginal rate of time preference equals the rate of interest, and

$$
\dot{b}=(y-\bar{z}) / p+r \bar{b}=0,
$$

ensuring external balance. The reason for doing so is that paths which converge to the stationary state satisfy the sufficiency condition for optimal controls,

$$
\lim _{\Delta \rightarrow \infty}\left[y / r p+b_{\Delta}\right] e^{-\Delta_{\lambda}} \lambda_{\Delta}=0
$$

and so, are optimal. ${ }^{10}$ we shall now show that there exists a unique convergent path, and that no divergent path is optimal. This, in turn, will guarantee that the economy's response to any change in the parameters it faces is uniquely determined.

\section{The Optimal Path}

Our analysis can be simplified by transforming the differential equations (11) and (12) into a system involving only $b$ and $z$. The necessary condition (10) shows that $\lambda_{t}$ can be written as a function of $b_{t}$ and $z_{t}$

$$
\lambda_{t}=\lambda\left(b_{t}, z_{t}\right)
$$

which may be differentiated and equated to (11) to yield

$$
\lambda_{b} \dot{b}_{t}+\lambda_{z} \dot{z}_{t}=\lambda\left(b_{t}, z_{t}\right)\left(\delta\left(V\left(p, z_{t}\right)\right)-r\right) .
$$


This implies the equation of motion for $z_{t}$,

(13)

$$
\begin{aligned}
\dot{z}_{t} & =\frac{\lambda\left(b_{t}, z_{t}\right)\left(\delta\left(V\left(p, z_{t}\right)\right)-r\right)-\lambda_{b}\left(b_{t}, z_{t}\right)\left(\left(y-z_{t}\right) / p+r b_{t}\right)}{\lambda_{z}\left(b_{t}, z_{t}\right)} \\
& \equiv \Psi\left(b_{t}, z_{t}\right) .
\end{aligned}
$$

of course, $\Psi(\vec{b}, \vec{z})=0$.

We now derive the system's phase portrait in a neighborhood of the stationary state by expanding (13) about $(\bar{b}, \bar{z})$. The resulting linear approximation is

$$
\begin{aligned}
\dot{z}_{t} & \simeq \bar{\Psi}_{b}\left(b_{t}-\bar{b}\right)+\bar{\Psi}_{z}(z t-\bar{z}) \\
& =-\frac{\bar{\lambda}_{b} r}{\bar{\lambda}_{z}}\left(b_{t}-\bar{b}\right)+\frac{\bar{\lambda} \bar{\delta}^{\prime} p \bar{v}_{z}+\bar{\lambda}_{b}}{p \bar{\lambda}_{z}}\left(z_{t}-\bar{z}\right),
\end{aligned}
$$

where a bar over a function indicates that it is evaluated at $(\bar{b}, \bar{z})$. Because

$$
\bar{\lambda}_{b}=-p^{2}\left(\bar{v}_{z}\right)^{2}\left(\bar{\delta}-\bar{v} \bar{\delta}^{\prime}\right) \bar{\delta}^{\prime} / \bar{\delta}, \quad \bar{\lambda}_{z}=p\left(\bar{v}_{z z}\left(\bar{\delta}-\bar{v} \bar{\delta}^{\prime}\right)-\bar{v} \bar{\delta}^{\prime \prime}\left(\bar{v}_{z}\right)^{2}\right) / \bar{\delta},
$$

(14) reduces to

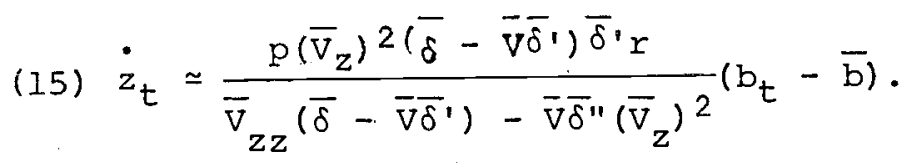




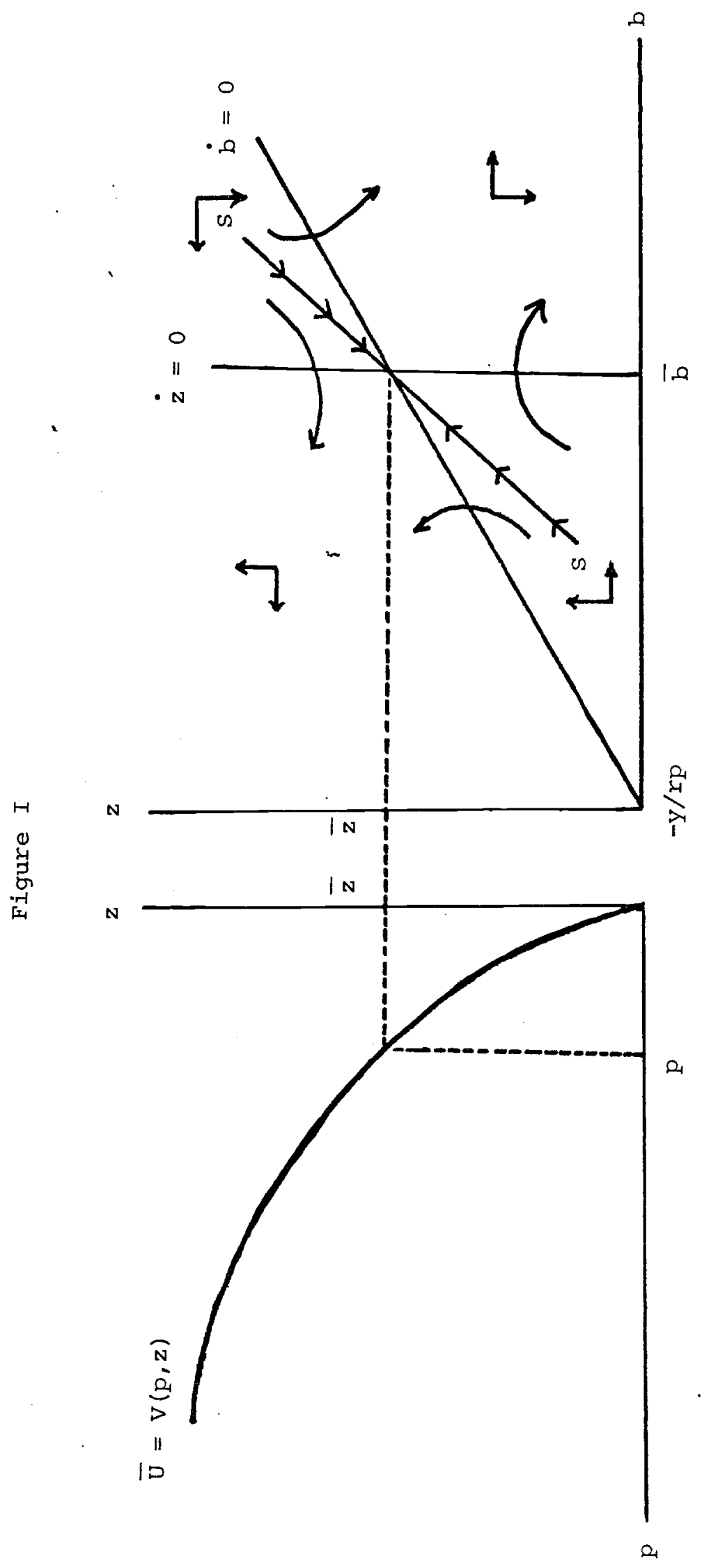


the system described by equations (12) and (15) in the region where the feasibility constraints $(7(\mathrm{iii}))$ and $(7$ (iv)) are respected. From (15), expenditure $\mathrm{z}$ is stationary provided bonds are at their long-run level $\bar{b}$; hence, the locus of points such that $\dot{z}=0$ is (locally) vertical. The assumptions made in (3) guarantee that spending is increasing to the left of this line and decreasing to its right. The locus along which $\dot{b}=0$ is upward sloping with slope

$$
\left.\frac{\mathrm{dz}}{\mathrm{db}}\right|_{\dot{\mathrm{b}}=0}=r \mathrm{p}
$$

for a rise in spending must be matched by a rise in interest income if the current account is to remain in balance. To the left of this schedule, income falls short of spending and bond holdinşs are decreasing; to its right, they are increasing. We note for future reference that the points $(0, y)$ and $(-y / r p, 0)$ always lie on the $\dot{b}=0$ locus.

The stationary state or long-run equilibrium $(\bar{b}, \bar{z})$ is a saddlepoint because of our assumptions regarding the shape of the time preference function. ${ }^{11}$ The path SS in Eigure 1 is the unique convergent path. From the sufficiency theorem for optimal controls cited above, we know that, given an initial value of $b$, it is optimal for the economy to choose an expenditure level placing it on the saddlepath SS. But it is now clear, in addition, that any other choice will be suboptimal. Paths originating below ss with $\mathrm{z}_{0}$ $\leq \bar{z}$ and $b_{0} \geq \bar{b}$ are dominated by the saddlepath; if $z_{0} \geq \bar{z}$ and $b_{0} \geq \bar{b}$, such a path is dominated by one that coincides with the original path until $\mathrm{z}_{\mathrm{t}}=\overline{\mathrm{z}}$ and remains at $\overline{\mathrm{z}}$ thereafter; and if $\mathrm{b}_{0} \leq \overline{\mathrm{b}}$, a path coinciding with the original one until the $\dot{b}=0$ schedule is crossed but holding spending constant thereafter dominates. Paths originating above SS entail a rising level of consumption over time. But consumption rises so quickly that the feasibility constraint that $y / r p+b$ be nonnegative eventually becomes binding. Thereafter, expenditure $z$ must fall sharply to zero in 
order to prevent any further growth in indebtedness, and this, by assumption (1), is not consistent with optimality. The unique path SS converging to long-run equilibrium at $(\bar{b}, \bar{z})$ must thus be the path the economy actually chooses. ${ }^{12}$

The two panels of Figure I together show how long-run equilibrium is determined. From the law of motion for $\lambda,(11)$, we see that the longrun utility level $\bar{U}$ is fixed by the relation

$$
\delta(\bar{U})=r,
$$

and so, is independent of the terms of trade. jires terms of trade $p$, theal, the economy's stationary-state expenditure level $\bar{z}$ must allow it to attain utility level $\bar{U}$, so that

$$
\text { (17) } V(p, \bar{z})=\bar{U} \text {. }
$$

Equation (17), which gives long-run expenditure in terms of domestic goods as a function of the terms of trade, is plotted in the left-hand panel of Figure I. By Roy's identity,

$$
\frac{d \bar{z}}{d p}=-v_{p}(p, \bar{z}) / V_{z}(p, \bar{z})=\bar{c}^{f}(p, \bar{U})
$$

showing that the function has the concave shape displayed in the diagram. Having found $\bar{z}$, we find the stationary stock of bonds. $\bar{b}$ by noting that for every choice of long-run consumption, there is only one level of bond holdings consistent with external balance. The $\dot{b}=0$ 
schedule of Figure I shows this relationship. A rise in stationarystate consumption must be financed by a higher stationary-state level of interest payments from abroad. This entails a higher stock of claims on foreigners in long-run equilibrium.

We observe, 'finally, that the saddlepath Ss does satisfy the intertemporal budget constraint (5). After substituting for $\mathrm{z}_{t}$ using (12) and integrating by parts, we find that

$$
\int_{0}^{\infty}\left[y+r p_{0}-z_{t}\right] e^{-r t} d t=\lim _{t \rightarrow \infty} p_{t} e^{-r t}
$$

This limit is certainly zero if $b_{t} \rightarrow \bar{b}<\infty$.

\section{Aggregate Spending and the Terms of Trade}

In this section we analyze the effects of a permanent terms-of-trade deterioration on aggregate expenditure measured in home goods and. on the current account. The initial income effect of this price movement depends, of course, on the size and sign of the economy's stock of claims on future units of the foreign good. For simplicity, we begin by assuming that bond holdings are zero. This corresponds to the case of complete specialization in production assumed by Laursen and Metzler and their contemporaries.

The hypothesized situation is depicted in Figure II. At the initial long-run equilibrium $\bar{E}$, the economy enjoys terms of trade $p$ and derives all its income from its fixed endowment $y$ of the home good. Consider now a rise from $\mathrm{p}$ to $\mathrm{p}^{\prime}$ in the relative price of the foreign good. The slope of the $\dot{b}=0$ schedule rises from rp to $r p^{\prime}$, the point $(0, y)$ remains consistent with external balance, and so the schedule rotates about 


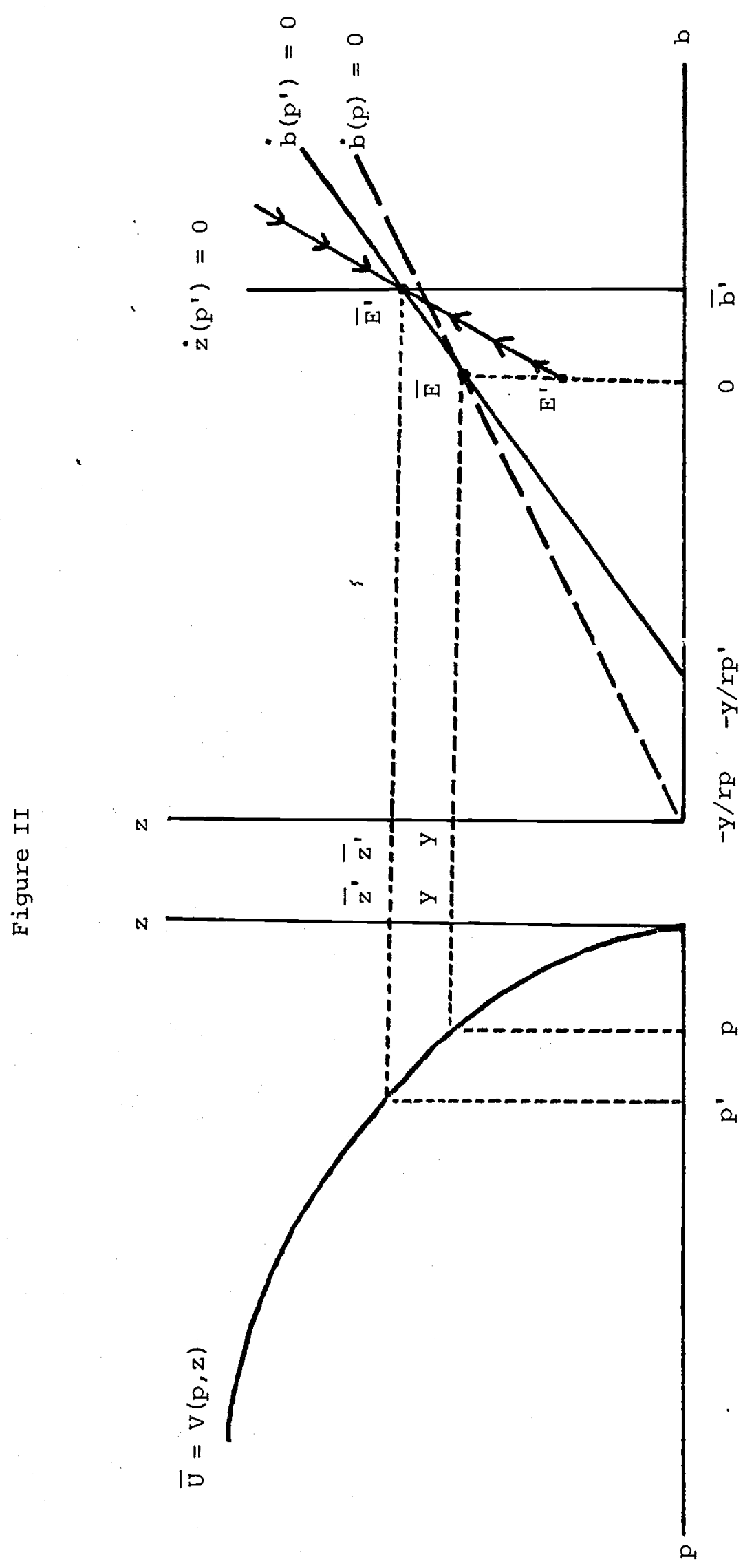


$\bar{E}$ in the counterclockwise sense. The left-hand panel shows that the stationary expenditure level rises to $\bar{z}^{\prime}$, and the new external balance locus shows the unique level $\bar{b}^{\prime}$ of bond holdings consistent in the long run with that level of spending. The convergent path leading to the postdisturbance stationary-state $\overline{E^{\prime}}$ necessarily passes below the initial position $\bar{E}$. The stock of net foreign claims cannot change instantaneously, so the economy jumps to point $E^{\prime}$ on the saddlepath when the terms of trade deteriorate. Contrary to the Laursen-Metzler presumption, the optimal response to the terms-of-trade shift requires a fall in the domestic-goods value of aggregate spending and a current-account surplus. The intuition behind this finding is easy to grasp. By (16), the economy will choose a transition path that allows it in the long run to attain its original utility level, $\bar{U}$. This implies that the permanent level of expenditure must rise from $\bar{z}$ to $\bar{z}$ '. The current account must eventually be in balance, however, and domestic spending measured in home goods cannot be higher in the new stationary state unless income is higher as well. A rise in income can be accomplished only through the gradual accumulation of interest-earning claims on foreigners. The terms-of-trade shift (in the present case) leaves the domestic-goods value of output unchanged, and so the required surplus must be accommodated by a fall in the domestic-goods value of expenditure. Figure II shows how consumption and bond holdings grow over time along the transition path to $\overline{\mathrm{E}}$ '.

It is instructive to ask why this reversal of the outcome predicted by Laursen and Metzler is possible. The Keynesian consumption function upon which the Laursen-Metzler argument is based posits a mechanical relationship between realized income and spending, 
according to which the household smooths the path of its consumption stream by reducing saving as well as spending in response to a worsening of the terms of trade. The result is a current-account deficit. However, an examination of the household's lifetime problem (8) shows why this reasoning is invalid in the present framework. Given its view of future prices, the family smooths the path of its future consumption stream; previous levels of real income are irrelevant. The point can be put another way. Expenditure will respond smoothly only to anticipated changes in real income. Unanticipated changes will convey new information and so dictate a revision of the lifetime consumption plan and a sharp change in spending. It is this sudden shift in expenditure that gives rise to a current-account surplus in the present setting.

We now consider the cases in which the economy's claims on the rest of the world are nonzero when the disturbance occurs. These may be thought of, of course, as cases of incomplete specialization in the exported commodity. When bond holdings are negative, the termsof-trade shift leads to a fall in the export value of income, and the export value of spending must decrease by a greater amount to deliver the current surplus required for the return to long-run equilibrium. But when net bond holdings are positive, the export value of income rises when the terms of trade turn against the home country, and so, an increase in the export value of consumption need not entail a current deficit. Figure III shows a case in which a positive expenditure response results from a sufficiently large endowment of claims on the foreign good. While in this instance the Laursen-Metzler spending effect is verified, nonspecialization is a necessary condition and a 


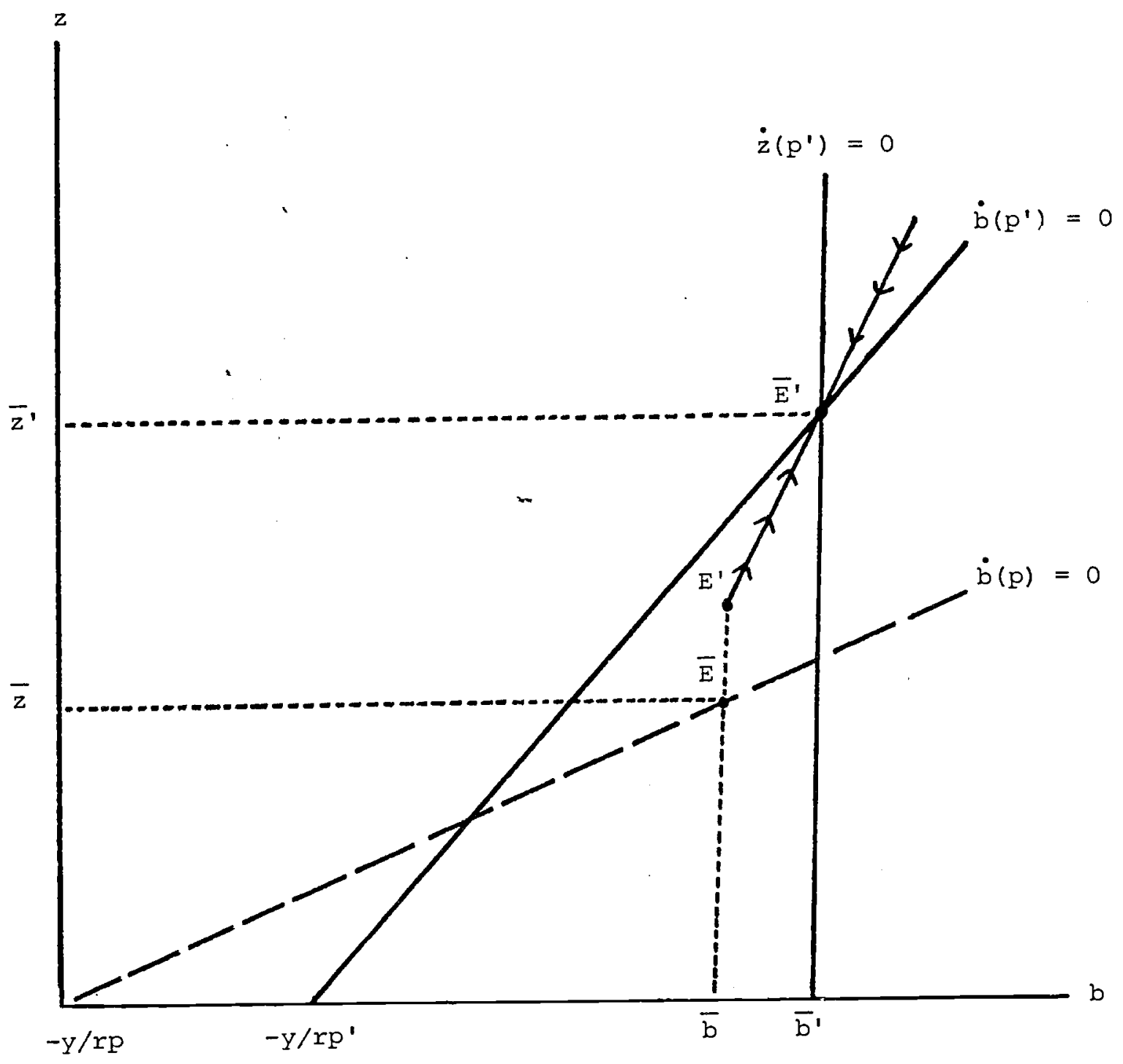

Figure III 
current deficit remains impossible. ${ }^{13}$

\section{An Imperfect Capital Market}

In this section we relax the assumption that the home country has access to a perfect world capital market willing to lend or borrow any amount at the going world rate of interest. We suppose instead that the cost of borrowing faced by the home country is an increasing function of its indebtedness to the rest of the world. This extension adds to the complexity as well as the realism of our analysis. While under perfect capital mobility, 'the representative household's eventual utility level $\bar{U}$ is a constant determined by line fixed worlci intirest rate $r$ alone, our new assumption implies that $\bar{U}$ and $r$ are jointly determined. In addition, we must describe how expectations regarding the future path of the interest rate are formed.

We assume now that the number of housenolds in the economy is 1 , that

(18) $r_{t}=r\left(b_{t}\right), \quad r^{\prime}\left(b_{t}\right)<0$,

and that the realized path of interest rates, $\left\{\hat{r}_{t}\right\}$, is a perfect-foresight equilibrium path. Under the last assumption, $\left\{\hat{r}_{t}\right\}$ has the property that when households behave competitively and maximize lifetime welfare in the belief that $\left\{\hat{r}_{t}\right\}$ is the path of interest rates that will prevail, the chosen path of bond holdings, $\left\{\hat{b}_{t}\right\}$, satisfies $\hat{r}_{t}=r\left(\hat{b}_{t}\right)$, for all t. 14 To find the set of paths consistent with the maximization hypothesis and the perfect-foresight assumption, note that the necessary conditions (12) and (13) remain applicable under competitive behavior. We need only substitute $r_{t}$ for $r$ using (18) in order to take into account the dependence of the interest rate on the 
stock of bonds. The stationary-state $(\bar{b}, \bar{z})$ of the resulting system continues to be characterized by the equality of the marginal rate of time preference and the interest rate,

$$
\delta(V(p, \bar{z}))=, r(\bar{b})
$$

and by external balance.

To investigate the system's dynamic properties in a neighborhood of the stationary-state, we may once again linearize (12) and (13) about $(\bar{b}, \bar{z})$, this time taking account of (18). The resulting approximation is

$$
\left[\begin{array}{c}
\dot{b} \\
\dot{z}
\end{array}\right] \simeq\left[\begin{array}{cc}
(1-\bar{n}) r(\bar{b}) & -1 / p \\
\bar{\Psi}_{b} & \bar{\Psi}_{z}
\end{array}\right]\left[\begin{array}{c}
b-\bar{b} \\
z-\bar{z}
\end{array}\right]
$$

where now

$$
\begin{aligned}
& \bar{\Psi}_{b}=\frac{p\left(\bar{v}_{z}\right)^{2}\left(\bar{\delta}-\bar{V}_{\bar{\delta}^{\prime}}\right) \bar{\delta}^{\prime}(1-\bar{n}) \bar{r}-\bar{v}_{z}\left(\bar{\delta}-\bar{v} \bar{\delta}^{\prime}\right) \bar{r}^{\prime}}{\bar{V}_{z z}\left(\bar{\delta}-\bar{v} \bar{\delta}^{\prime}\right)-\bar{v} \bar{\delta}^{\prime \prime}\left(\bar{v}_{z}\right)^{2}}, \\
& \bar{\Psi}_{z}=\frac{\bar{V}_{z}^{2}\left(\bar{\delta}-\bar{v} \bar{\delta}^{\prime}\right) \bar{\delta}^{\prime} \bar{\eta}}{\bar{v}_{z z}\left(\bar{\delta}-\bar{v} \bar{\delta}^{\prime}\right)-\bar{v} \bar{\delta}^{\prime \prime}\left(\bar{v}_{z}\right)^{2}},
\end{aligned}
$$

and $n \equiv-b r^{\prime}(b) / r$. On the assumption that $|\eta|<1$, so that interest income can never decrease as bond holdings increase, the determinant 
of the system (19) is negative. ${ }^{15}$ since the latter is the product of the system's characteristic roots, (19) must possess one negative root and one positive root, implying the existence of a unique saddlepath converging to the stationary position $(\bar{b}, \bar{z})$. It is straightforward to show that this convergent path is the sole perfect-foresight equilibrium path for the economy. 16

Once again, the saddlepath satisfies the intertemporal budget constraint, which is now written as

$$
b_{0}+\int_{0}^{\infty}(y / p) e^{-\rho_{t}} d t-\int_{0}^{\infty}\left(z_{t} / p\right) e^{-\rho_{t}} d t=0
$$

where $\rho_{t} \equiv \int_{0}^{t} r\left(b_{s}\right) d s$. The left-hand side of (20), after a change of variables from t to $\rho$, becones

$$
b_{0}+\int_{0}^{\infty}\left(\frac{d b}{d \rho}-b_{\rho}\right) e^{-\rho} d \rho=\lim _{\rho \rightarrow \infty} b_{\rho} e^{-\rho}
$$

This limit is zero provided $b_{\rho}$ converges to a finite value. In Figure IV we depict the joint determination of the long-run equilibrium interest rate $\bar{r}$ and utility level $\bar{U}$. Let $\beta(r)$ be the level of bond holdings associated with interest rate $r$. The equation

(21) $\quad U=V(p, y+r \beta(r))$

shows that a higher long-run utility level requires a higher longrun level of interest payments from abroad and so (because $|\eta|<1$ ) a lower long-run interest rate. This gives the downward sloping rela- 


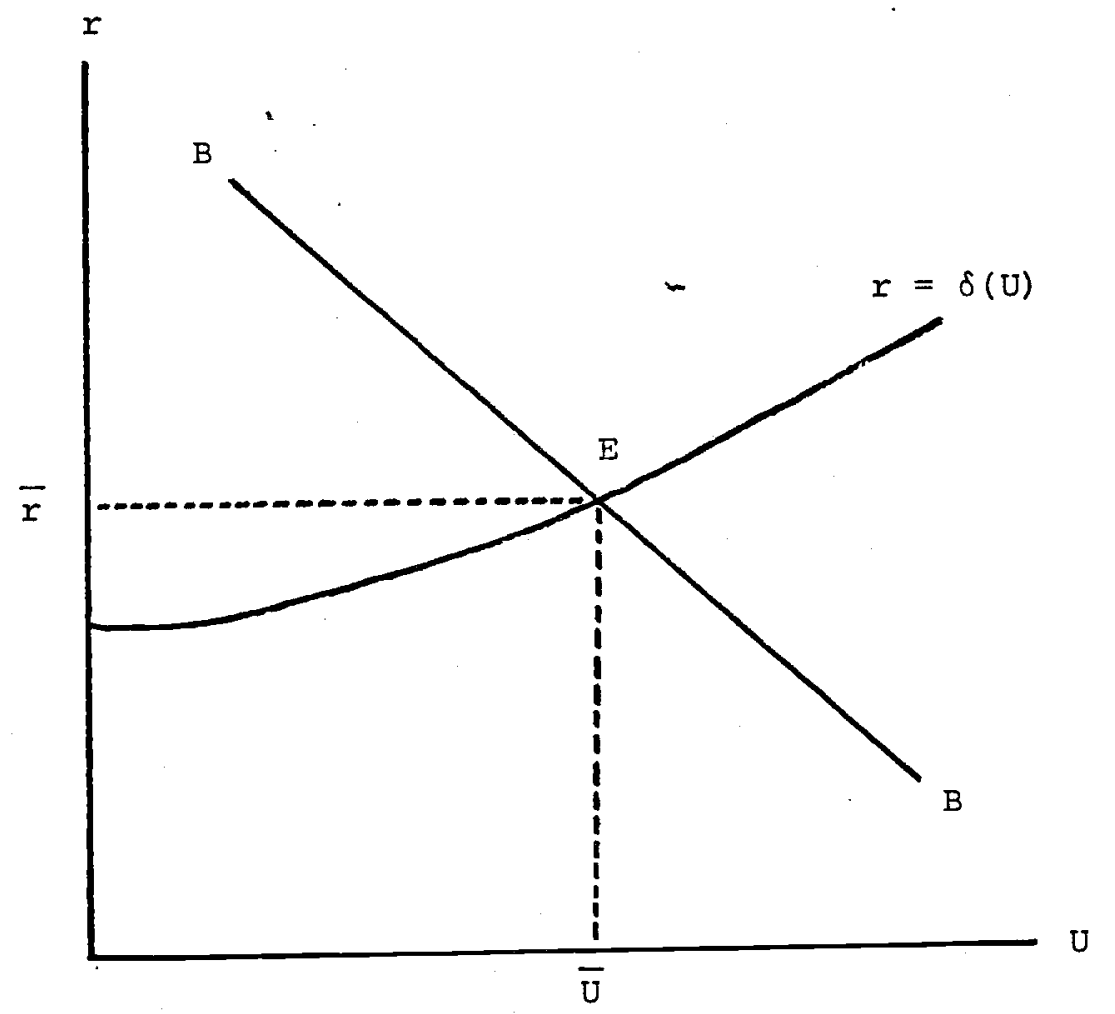

Figure IV 
tionship BB shown in Figure IV. The upward-sloping relationship reflects the equality of the interest rate and rate of time preference that must obtain in the stationary state. Long-run equilibrium must be consistent with both of these relationships. The long-run values of utility and the interest rate are thus determined by the intersection of the two schedules at $\mathrm{E}$.

We now consider the effects on the stationary utility level and interest rate of a permanent, adverse shift in the terms of trade. From (21), the position of the BB schedule depends on $p$. If $p$ rises to $p^{\prime}$, the economy will enjoy a lower long-run utility level for any level of interest income, and so the BB schedule shifts leftward to $B^{\prime} B^{\prime}$ as Figure $V$ shows. Thus, a rise in the relative price of imports leads to lower utility and a lover interest rate in stationary-state equilibrium.

Recalling our result that the system's stationary state is a saddlepoint, it is easy to characterize the dynamics of the transition path leading there. A lower long-run interest rate implies higher net bond holdings than before the disturbance, and the terms-of-trade shift must therefore cause a current-account surplus on impact. Whether spending in terms of exportables rises or falls will again depend on the economy's initial holdings of claims on foreign output. When net claims are zero, so that the economy is, in effect, specialized, a current surplus requires

a fall in the export value of expenditure.

Consideration of the case where the capital market is imperfect reinforces our earlier conclusions regarding the effect of terms-of-trade change on absorption and the external balance. In addition, it shows how a fall in the relative price of exports may cause a decline in the 


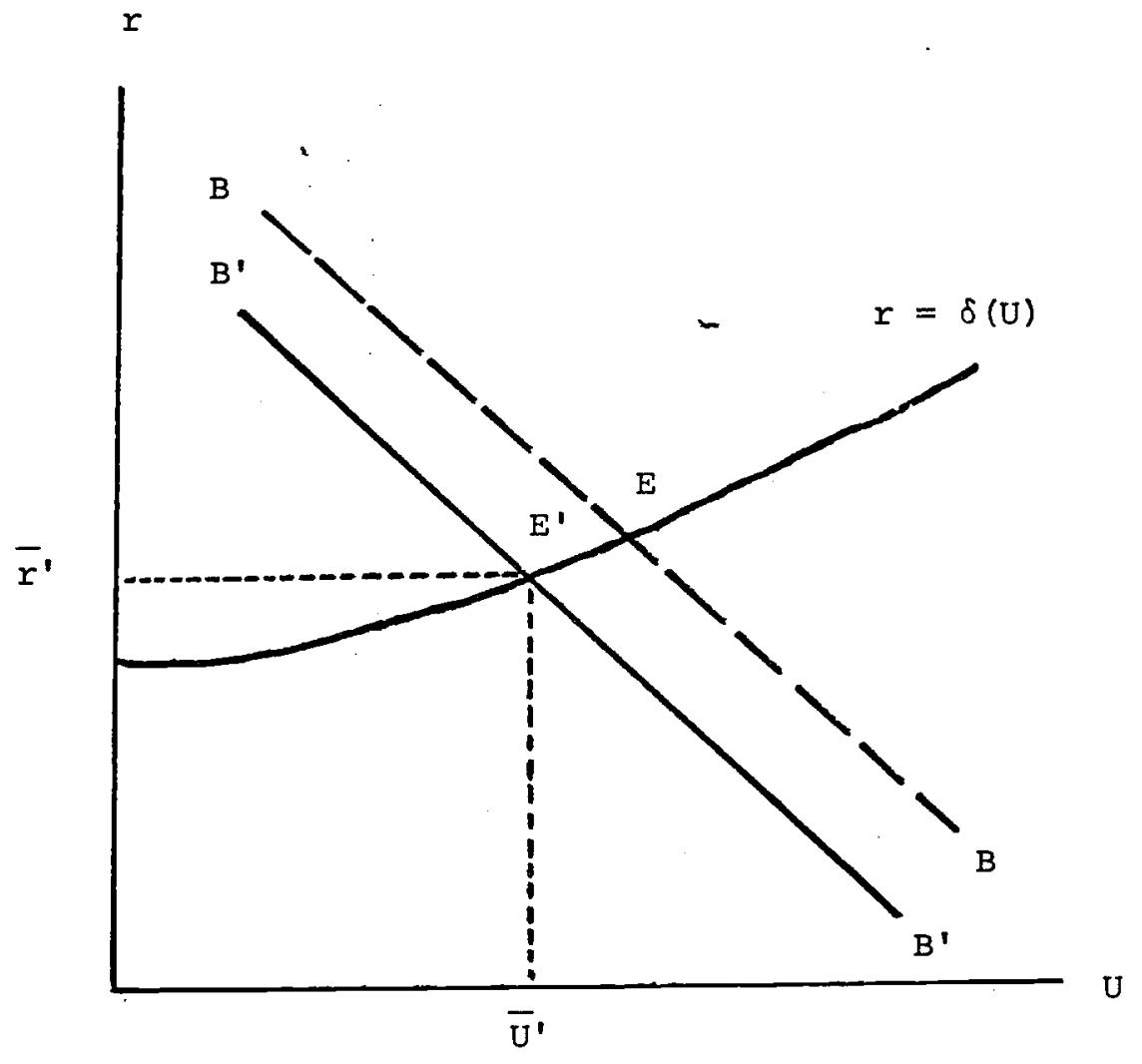

Figure V 
economy's permanent, long-run utility level.

\section{v. Conclusion}

This paper has studied the expenditure and current-account effects of a permanent terms-of-trade deterioration in an economy of infinitely-lived, utility-maximizing families. In this context of explicit, intertemporal optimization, we found that the well-known Laursen-Metzler relationship predicting a current deficit and a rise in the export value of spending is invalid. A deterioration in the terms of trade, in our setting, leads to a current surplus as households acquire interest-bearing claims on foreigners in order to restore their stationary-state real income to its original level. This entails a fall in the home-good value of spending when initial bond holdings are zero, but may be coupled with a rise in that variable when initial claims on future units of the import are positive.

These findings have arisen under a particular set of assumptions concerning preferences and the opportunites for transforming present utility into future utility. And, indeed, the interemporal transformation possibilities assumed here have differed form those assumed by Laursen and Metzler, who envisioned a monetary economy with a floating exchange rate, unable to borrow or lend abroad. The validity of the Laursen-Metzler prediction depends in general on the economy's intertemporal utility possibilites and its menu of assets. We have analyzed only one of many possible cases. Nonetheless, the example analyzed here throws doubt on the notions underlying the Keynesian consumption function from which the Laursen-Metzler prediction is derived. Aggregate relationships that link consumption only to 
measured income or wealth fail to account for the impact of unanticipated changes in the perceived lifetime budget constraint, changes that call for a revision of the entire planned future consumption path. Recent aiscussion of the current-account "adjustment problem" associated with terms-of-trade shocks to the industrialized economies has, for the most part, ignored this point.

\section{Appendix}

In this appendix, we show that the indirect utility function $V(p, z)$ is concave in $z$ when the underlying utility function $U\left(c^{f}, c^{h}\right)$ is concave. To see this, write indirect utility as

$$
V(p, z)=\max _{c}\{U(c, z-p c)\}
$$

Let $V\left(p, z^{\prime}\right)=U\left(c^{\prime}, z^{\prime}-p c^{\prime}\right)$ and $V\left(p, z^{\prime \prime}\right)=U\left(c^{\prime \prime}, z^{\prime \prime}-p c^{\prime \prime}\right)$, and suppose $\lambda \varepsilon[0,1]$. Then

$$
\begin{aligned}
\lambda V\left(p, z^{\prime}\right)+ & (1-\lambda) V\left(p, z^{\prime \prime}\right)=\lambda U\left(c^{\prime}, z^{\prime}-p c^{\prime}\right)+(1-\lambda) U\left(c^{\prime \prime}, z^{\prime \prime}-p c^{\prime \prime}\right) \\
& \leq U\left(\lambda c^{\prime}+(1-\lambda) c^{\prime \prime}, \lambda z^{\prime}+(1-\lambda) z^{\prime \prime}-\lambda p c^{\prime}-(I-\lambda) p c^{\prime \prime}\right) \\
& \leq \max _{c}\left\{U\left(c, \lambda z^{\prime}+(1-\lambda) z^{\prime \prime}-p c\right)\right\} \\
& =V\left(p, \lambda z^{\prime}+(1-\lambda) z^{\prime \prime}\right) .
\end{aligned}
$$

where the first inequality is a consequence of the concavity of $U(\cdot, \cdot)$. 


\section{Notes}

1. Laursen and Metzler [1950].

2. Johnson [1967] includes a survey of previous writing on the LaursenMetzler relationship, while Mussa [1979] and Dornbusch [1980] provide more recent treatments. Interest in the macroeconomic consequences of terms-of-trade disturbances has until recently been "crowded out" by the one-good paradigm associated with the monetary approach to the balance of payments. An exception is Rodriguez [1976], who attempts to deal with terms-of-trade questions within the framework of the monetary approach.

3. Keynes [1936], p. 96 .

4. This paper's assumption that the subjective rate of time preference is a function of contemporaneous utility allows the small economy described in Section I to attain a stationary state under perfect capital mobility. Findlay [1978] provides another example of this type of assumption, and a discussion. The economy described in section IV could attain a stationary state even if the subjective rate of time preference were constant, as is usual in optimal

control problems. But the resulting model would have the unrealistic implication that a terms-of-trade change has no effect on the current account when the economy is initially in external balance. Svensson and Razin [1981], in a two-period model, show that the current-account effect of a permanent terms-of-trade change depends on whether the subjective time preference rate is increasing or decreasing in the level of instantaneous utility. We make the former assumption in (3), below; the latter assumption excludes the possibility of a convergent optimal accumulation path in an infinite-horizon setting (see $\mathrm{n}$. 11 below), and thus renders our smallcountry assumption untenable. Note also that we have not analyzed the effects of transitory terms-of-trade shocks in this paper.

5. If we allowed some lending to be indexed to the home good as. well, the economy would be able to vary its endowment of both goods. But this would 
have no bearing on the results derived below.

6. This assumption allows us to speak of "the" rate of interest.

7. It may be helpful to note that if instantaneous utility is constant at level $U$, discounted lifetime utility is $U / \delta(U)$, and the second inequality in (3) asserts that this quotient rises as U rises.

8. This is the solution proposed by Arrow and Kurz [1969], who provide a more detailed discussion of the problem raised by perfect capital markets. The paper is reprinted as chapter VII of Arrow and Kurz [1970].

9. See Arrow and Kurz [1970].

10. The form in which this condition is stated requires comment. The sufficiency theorem assumes that the state variable (in this case, b) is always non-negative (see Arrow and Kurz (1970), p. 45); indeed, we have seen that the sufficiency theorem must break down if we allow unlimited borrowing from abroad, since it is then easy to dominate the saddlepath. If we define "total assets" as the sum of bond holdings plus the discounted future flow of the home good, $a \equiv b+y / r p$, the flow constraint may be written $\dot{a}_{t}=r a_{t}-z_{t} / p$. Carrying out the optimization exercise (7) with a instead of $b$ as state variable, we obtain necessary conditions identical with those appearing in the text. But since (7) imposes the constraint $a \geq 0$, the condition $\lim _{\Delta \rightarrow \infty} a_{\Delta} e^{-\Delta_{\lambda}}=0$ is sufficient for optimality. This is just the criterion invoked hero.

11. When $\delta^{\prime}(U)<0$ (contrary to the assumption of (3)) but the maximand $V(p, z) / \delta(V(p, z))$ remains concave, the system described by (12) and (15) possesses two characteristic roots with positive real part. This means that there exists no path converging to the stationary state. Further, for given $b_{0}$, there may be no optimal feasible expenditure path. 
12. It is interestirig to note that along the saddlepath, saving in terms of home goods is given by the "Metzlerian" function $p \theta\left(b_{t}-\bar{b}\right)$, where $\theta=$ $\left(r-\sqrt{r^{2}-4 \bar{\Psi}_{b} / p}\right) / 2<0$. of course, this formula is applicable only so long as no unanticipated disturbances move the optimal path.

13. There exist terms of trade so adverse that the "home" good becomes an import in the stationary state. But the long-run level of bond holdings must rise as long as the home good is being exported initially.

14. Our assumption of competitive behavior implies that the interest rate perceived by households will differ from the economy's true marginal rate of transformation between future and present goods. This type of divergence is familiar from the optimal tariff literature, and can be corrected by appropriate government fiscal intervention. The government's problem is a dynamic one in the present context, however. 15. The determinant is

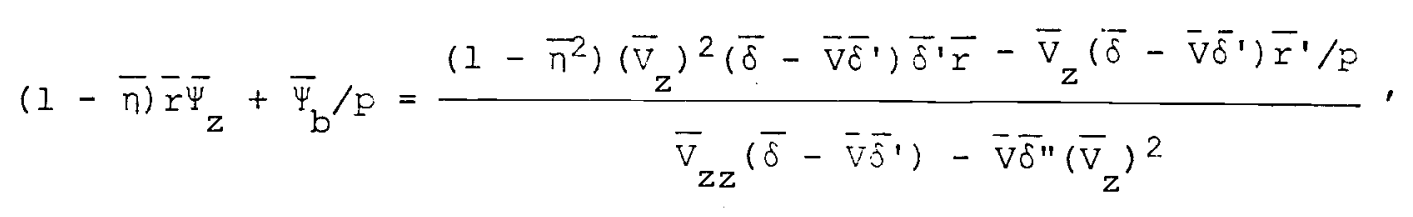

which is clearly negative provided $|n|<1$.

16. Because the saddlepath is convergent, it satisfies the optimal control sufficiency theorem (cf. n. 10) and is thus a perfect-foresight equilibrium path. Feasible, non convergent paths entail ever-rising income but perpetually falling consumption. They therefore cannot be equilibrium paths, for agents would never willingly pick the paths of bond holdings generating the associated paths of the interest rate. 


\section{References}

Alexander, S.S, "Effects of a Devaluation on a Trade Balance," International Monetary Fund Staff Papers, II (April 1952), 263-78.

Arrow, K.J., and M. Kurz, "Optimal Consumer Allocation over an Infinite Lifetime," Journal of Economic Theory, I (June 1969), 68-91.

Arrow, K.J., and M. Kurz, Public Investment, the Rate of Return, and Optimal Fiscal'Policy (Baltimore: The Johns Hopkins Press, 1970).

Dornbusch, R., Open Economy Macroeconomics (New York: Basic Books, 1980).

Findlay, R., "An 'Austrian' Model of International Trade and Interest Rate Equalization," Journal of Political Economy, LXXXVI (Dec. 1978), 9891008.

Harberger, A.C., "Currency Depreciation, Income and the Balance of Trade," Journal of Political Economy, 'LVIII (Eeb. 1950), 47-60.

Jonnson, H.G., "The I'ransfer Problen and Exchange stability," in Intelnat:o:la: Trade and Economic Growth (Cambridge: Harvard University Press, 1967).

Keynes, J.M., The General Theory of Employment Interest and Money (London: Macmillan, 1936).

Laursen, S., and L.A. Metzler, "Flexible Exchange Rates and the Theory of Employment," Review of Economics and Statistics, XXXII (Nov. 1950), 28199.

Mussa, M., "Macroeconomic Interdependence and the Exchange Rate Regime," in R. Dornbusch and J.A. Frenkel, eds., International Economic Policy: Theory and Evidence (Baltimore: The Johns Hopkins University Press, 1979).

Rodriguez, C.A., "The Terms of Trade and the Balance of Payments in the Short Run," American Economic Review, LXVI (Sept. 1976), 710-16.

Svensson, L.E.O., and A. Razin, "The Terms of Trade, Spending, and the Current Account: The Harberger-Laursen-Metzler Effect," unpublished manuscript. Institute for International Economic studies, Stockholm, 1981 .

Uzawa, H., "Time Preference, the Consumption Function, and Optimum Asset Holdings," J.N. Wolfe, ed., Value, Capital and Growth: Papers in Honour of Sir John Hicks (Chicago: Aldine Publishing Company, 1968). 